\title{
Doctors' shortage in adults COVID-19 units: a call for pediatricians
}

\author{
Danilo Buonsenso $^{1,2,3}$ (D) Cristina De Rose ${ }^{1} \cdot$ Luca Pierantoni $^{2}$
}

Received: 9 November 2020 / Revised: 24 January 2021 / Accepted: 10 February 2021 / Published online: 16 February 2021

(C) The Author(s), under exclusive licence to Springer-Verlag GmbH, DE part of Springer Nature 2021

\begin{abstract}
Since its first description in China, SARS-CoV-2 has been spreading all over the world causing millions of 31 infections and hundreds of thousands of deaths. The massive raise of cases all over the world even during the current second wave is leading to unprecedented pressures on healthcare services. Growing evidence is highlighting that COVID-19 is a systemic condition that requires doctors with multiple expertise. Paediatricians are trained in these skills. Considering the issue of staff shortage that is facing every country in the world, and the complexity of COVID-19, pediatricians may represent an important source of ready and skilled specialists that can quickly translate the pediatric practice in the COVID-19 care. In conclusion, we highlight through our experience several parallels between the pediatric clinical practice and clinical conditions described in patients with COVID-19 as well as the diagnostic tools and the measures taken in 39 patients with COVID-19.
\end{abstract}

\section{What is Known:}

- The massive raise of cases all over the world is leading to unprecedented pressures on healthcare services.

- Growing evidence is highlighting that COVID-19 is a systemic condition that requires doctors with multiple expertise.

What is New:

- Pediatricians are trained daily in these skills.

- Considering the issue of staff shortage that is facing every country in the world, and the complexity of COVID-19, pediatricians may represent an important source of ready and skilled specialists that can quickly translate the pediatric practice in the COVID-19 care.

Keywords Coronavirus · COVID-19 · Doctors' shortage $\cdot$ Adults units $\cdot$ Children $\cdot$ Pediatricians

\author{
Abbreviations \\ Communicated by Nicole Ritz \\ Danilo Buonsenso \\ danilobuonsenso@gmail.com \\ Cristina De Rose \\ cristyderose@gmail.com \\ Luca Pierantoni \\ lucapierantoni82@gmail.com
}

SARS-CoV-2 Severe acute respiratory syndrome coronavirus 2 COVID-19 Coronavirus disease 19

1 Department of Woman and Child Health and Public Health, Fondazione Policlinico Universitario A. Gemelli, Rome, Italy

2 Dipartimento di Scienze Biotecnologiche di Base, Cliniche Intensivologiche e Perioperatorie, Università Cattolica del Sacro Cuore, Bologna, Italy

3 Global Health Research Institute, Istituto di Igiene, Università Cattolica del Sacro Cuore, Roma, Italy

$\begin{array}{ll}\text { CPAP } & \text { Continuous positive airway pressure } \\ \text { LUS } & \text { Lung ultrasound } \\ \text { CT } & \text { Computed tomography }\end{array}$

Since its first description in China, SARS-CoV-2 has been spreading all over the world causing millions of infections and hundreds of thousands of deaths.

Since late summer, countries across Europe are seeing a resurgence in COVID-19 cases after successfully slowing outbreaks early in the year. In particular, a relaxation of lockdowns and the public's loosening of precautionary behaviors has seen recorded cases and deaths rise across Europe. While governments once again move to slow the spread of the virus, the hospitals fill up once again and health workers are on the front lines of the epidemic again [1].

Both during the first wave and currently during the second wave, the massive raise of cases all over the world led to unprecedented pressures on healthcare services. Several 
hospitals have again changed their organization in order to increase critical care capacity and isolation areas and to generate new flows to guarantee safety and care to non-COVID patients. Outpatient services and community medicine suddenly faced the difficulties with a safe assessment of patients, and a rapid shift to telemedicine services has been empowered. Several hospitals have cancelled non-COVID operations and staff holidays as they shift to emergency working, with doctors in different countries of Europe saying that this wave is already "worse than the first" [1].

The past, current, and projected scale of distress among healthcare professionals, while understandable, has been and is of grave concern [2]. The short- and long-term negative effects of this disease have the potential to have both physical and psychological consequences impacting significantly on the quality of life of both of the health worker and their family [3]. The existing risks to the well-being of healthcare professionals are compounded under the current highly pressurized conditions [2].

The whole world is facing a severe shortage of personal protective equipment [4], which contributes to the high number of infections, disease, and deaths among healthcare workers worldwide, as well as contributing in this way to the spread of the infection itself.

Lack of personal protective equipment (PPE) and inadequate PPE were commonly cited as a cause of death especially in developing nations and Italy [5].

Having adequate numbers of health workers will be critical to winning the battle against COVID-19.

Access to personal protective equipment, occupational safety and health protocols, adequate rest and recovery periods, and other working conditions will determine how effectively health workers can treat patients. Altogether, these factors, if lacking, determine themselves an increasing shortage of doctors worldwide, including the richest countries.

Although the CDC provided strategies to mitigate healthcare personnel staffing shortages (https://www.cdc. gov/coronavirus/2019-ncov/hcp/mitigating-staffshortages.html), each country was forced to implement independent approaches. For example, the Italian government allowed the official engagement of newly graduated medical doctors or last-years residents in order to face the shortage of doctors (https://www. washingtonpost.com/world/europe/coronavirus-in-italyfills-hospital-beds-and-turns-doctors-into-patients/2020/ 03/03/60a723a2-5c9e-11ea-ac50-18701e14e06d_story. html). In the USA, several medical schools allowed fourthyear medical students to graduate early or return to the hospital to support in daily activities (https://www.aamc. org/news-insights/itching-get-back-medical-studentsgraduate-early-join-fight; https://www.aamc.org/newsinsights/i-m-fourth-year-medical-student-i-don-t-wantgraduate-early).
Other institutions shifted medical specialists without a specific experience in COVID-19-like situations (e.g., surgeons, ophthalmologists, dermatologists) to work on COVID-19 units (https://www.nytimes.com/2020/03/23/health/ coronavirus-doctors-specialists.html).

Since the beginning of the SARS-CoV-2 spread outside China, pediatric practice has changed completely. Luckily, SARS-CoV-2 is rarely involving children, and most of the time, pediatric COVID-19 disease is mild [6, 7]. Moreover, parents stopped to routinely bring their children to the hospital either because of fear in contracting the infection or due to a lockdown-related drop of seasonal infectious diseases [8].

As a consequence, the workload of pediatricians has significantly reduced in these months [4], and therefore their inclusion in COVID-19 units should be considered by institutions. Although not directly involved in adult care, pediatricians may play a significant role in managing COVID-19-like patients for several reasons.

The pediatricians who could be more facilitated to take care of adult COVID-19 patients are those pediatricians who deal with child pathologies globally (such as primary care pediatricians, first aid pediatricians, pediatricians in general pediatric wards, pediatric intensive and sub-intensive therapy pediatricians ) or infectious disease pediatricians and pediatric pneumologist pediatricians.

These above categories of pediatricians may have some of the capability needed to treat adult COVD-19. Conversely, a pediatric allergologist or a neonatologist or a pediatric oncologist or the pediatricians working in big specialized pediatric hospitals where they only practice their subspecialty and do not see the whole pie for several years may more or less fail on this or find themselves in a discomfort situation as well as other specialists who have already been called to work in COVID-19 departments (neurological, surgeons, orthopedists) [9]. Obviously this very much depends not only on the training but also in the setting where they are working.

From a clinical point of view, some of the above categories of pediatricians routinely take care of patients with viral conditions and acute respiratory distress (e.g., bronchiolitis, asthma) and that's why are confident in diagnosis and treatment. The usual management of these situations provide expertise in blood-gas analysis evaluation and in the use of devices for respiratory support, such as high-flow nasal cannula and continuous positive airway pressure (CPAP). In addition, recent evidence is pointing out that adult COVID-19 resembles systemic inflammatory syndromes [10] and pediatricians are not new to such conditions. For instance, Kawasaki disease is one of the most common systemic conditions in children, and, not rarely, biological agents are required to treat it, not to mention the new identity of pediatric inflammatory multisystem syndrome temporally associated with COVID-19 (PIMS-TS) [11]. Similarly, macrophage activation syndromes, as well as 
other rheumatologic conditions, do occur in secondary and tertiary level settings increasingly requiring from pediatricians to be trained in managing biological agents.

Another pediatric skill in continuous evolution today that can certainly encourage pediatricians to support adult colleagues caring for COVID-19 patients is the use of lung ultrasound (LUS) also in pediatric clinical practice by an increasing number of pediatricians [12-14].

Given their skills in pediatric infectious diseases and lung ultrasound, pediatricians D.B. and L.P. have been included in the management of adults with COVID-19 in their institutions (5 weeks of experience in obstetric COVID ward and in an adult COVID ward, respectively), as well as many other colleagues in Italy.

Together with pediatric intensivists who have been called back to manage adult patients, in some centers, pediatricians answered the national call of help.

Although they could face several limits dealing with adult patients (and we really did!), the habit to manage complex patients with multi-systemic diseases and poly-pharmacological therapies gives pediatricians an important source of strength to contribute to the management of adult COVID-19 patients.

Probably all these strengths could also reduce the anxiety, stress, and feeling of uncertainty that doctors who find themselves working in a different field from which they were trained can feel.

On the other hand, the major barrier could be represented by medico-legal concerns, as common comorbidities and complications of adult patients are far from the pediatric daily practice. A safe and effective strategy for COVID wards could be once again a multidisciplinary team. A close collaboration between pediatricians and internists (even mixing more and less experienced doctors) could be precious to re-introduce the former to adult patients and to ensure mutual clinical support.

In Bologna two internists, two pediatricians (including L.P.), one endocrinologist, and a group of mixed pediatric and internist residents managed a 30-bed COVID ward.

In Rome, D.B. became responsible for LUS evaluation of pregnant women with respiratory conditions, in order to reduce the routine use of chest X-rays and computed tomography (CT) scans in this specific group, reserving these tools to selected cases [14].

It must be said that the dynamics of a pandemic change with time and from country to country, including the dynamics and health needs both at hospital and territorial level.

The potential use of pediatricians to help in the management of COVID-19 adult patients must be carefully weighed against the risk to harm many children and neonates.

During pandemics many clinical activities have been delayed or even canceled to allow clinicians of other specialties to work on COVID19.

This obviously does not have to happen also for pediatric care because it would be a serious damage for many public health systems and for society itself.
If on the one hand, the involvement of COVID-19 in children is rare and mild and parents stopped to routinely bring their children to the hospital either because of fear in contracting the infection or due to a lockdown-related drop of seasonal infectious diseases [6-8], some categories of pediatricians have remained and remain essential. For example, pediatricians caring for children with disabilitie should continue with routine follow-up and medical care to avoid any complications, or neonatologists will need to care for babies that continue to be delivered and that will always need a pediatrician both at birth and in the first months of life. But also ICU pediatricians are essential for the care of critically ill children.

In this perspective, there are other categories of doctors that can be used to reduce the health pressure caused by the pandemic, such as military doctors who are adult doctor specialist in ICU, and sometimes also internal medicine, cardiology, or pneumology. Again, their role and use must be weighed in relation to their need in countries engaged in wars.

In conclusion, growing evidence is highlighting that COVID-19 is a systemic condition that requires doctors with multiple expertise [15]: general support measures, experience in managing antivirals, antibiotics and biological agents, respiratory support, imaging interpretation, and experience in point-of-care ultrasound.

Pediatricians are trained in these skills, especially certain categories. Considering the issue of staff shortage that is facing every country in the world, the complexity of COVID-19, the rare and mild involvement of SARSCoV-2 in children [6, 7], and the reduced access to pediatric health facilities [8], some categories of pediatriciansthose temporarily less involved in the care of children and newborns - may represent an important source of ready and skilled specialists that can quickly translate the pediatric practice in the COVID-19 care, helping to reduce current health pressure, always paying attention not to damage the different categories of children.

Acknowledgements We are grateful to Prof Antonia Testa, scientific manager of the Center of Ultrasound in Oncological Gynecology, "Class Ultrasound", of A. Gemelli University Hospital, in Rome, Italy; Prof Piero Valentini, head of the Pediatric Unit of Infectious Diseases of the A. Gemelli University Hospital, in Rome, Italy; and Prof Marcello Lanari, head of Pediatric Emergency Unit of S. Orsola University Hospital in Bologna, Italy.

Authors' contributions DB and LP conceptualized the study and wrote the manuscript. DB and CDR collected data and were responsible for data analyses. All authors read and approved the final manuscript as submitted and agree to be accountable for all aspects of the work.

\section{Availability of data and material N/A}

Code availability N/A 


\section{Declarations}

Ethics approval This article does not contain any studies with human participants or animals performed by any of the authors.

\section{Consent of participate N/A}

Consent for publication N/A

Competing interests The authors declare no competing interests.

\section{References}

1. Looi M-K (2020) Covid-19: Is a second wave hitting Europe? BMJ $371: \mathrm{m} 4113$

2. Harriss A (2020) In this issue of occupational medicine. Occup Med 70(5):293

3. Kinman G, Teoh K, Harriss A (2020) Supporting the well-being of healthcare workers during and after COVID-19. Occup Med 70(5): 294-296

4. Bressan S, Buonsenso D, Farrugia F (2020) Parri N et al Preparedness and Response to Pediatric COVID-19 in European Emergency Departments: A Survey of the REPEM and PERUKI Networks. Ann Emerg Med. 76(6):788-800. https://doi.org/10. 1016/j.annemergmed.2020.05.018

5. Salvatori G (2020) Italian doctor dies of coronavirus after working without gloves due to shortage. Euronews 2020. https://www. euronews.com/2020/03/18/italian-doctor-dies-of-coronavirusafter-working-without-gloves-due-to-shortage

6. Viner RM, Mytton OT, Bonell C, Melendez-Torres GJ, Ward J, Hudson L, Waddington C, Thomas J, Russell S, van der Klis F, Koirala A, Ladhani S, Panovska-Griffiths J, Davies NG, Booy R, Eggo RM (2021) Susceptibility to SARS-CoV-2 Infection Among Children and Adolescents Compared With Adults: A Systematic Review and Meta-analysis. JAMA Pediatr. 175(2):143-156. https://doi.org/10.1001/jamapediatrics.2020.4573

7. Götzinger F, Santiago-García B, Noguera-Julián A, Lanaspa M, Lancella L, Calò Carducci FI, Gabrovska N, Velizarova S, Prunk P, Osterman V, Krivec U, Lo Vecchio A, Shingadia D, SorianoArandes A, Melendo S, Lanari M, Pierantoni L, Wagner N, L'Huillier AG, Heininger U, Ritz N, Bandi S, Krajcar N, Roglić S, Santos M, Christiaens C, Creuven M, Buonsenso D, Welch SB, Bogyi M, Brinkmann F, Tebruegge M, Pfefferle J, Zacharasiewicz A, Berger A, Berger R, Strenger V, Kohlfürst DS, Zschocke A, Bernar B, Simma B, Haberlandt E, Thir C, Biebl A, vanden Driessche K, Boiy T, van Brusselen D, Bael A, Debulpaep S, Schelstraete P, Pavic I, Nygaard U, Glenthoej JP, Heilmann Jensen L, Lind I, Tistsenko M, Uustalu Ü, Buchtala L, Thee S, Kobbe R, Rau C, Schwerk N, Barker M, Tsolia M, Eleftheriou I, Gavin P, Kozdoba O, Zsigmond B, Valentini P, Ivaškeviciene I, Ivaškevicius R, Vilc V, Schölvinck E, Rojahn A, Smyrnaios A, Klingenberg C, Carvalho I, Ribeiro A, Starshinova A, Solovic I,
Falcón L, Neth O, Minguell L, Bustillo M, Gutiérrez-Sánchez AM, Guarch Ibáñez B, Ripoll F, Soto B, Kötz K, Zimmermann P, Schmid H, Zucol F, Niederer A, Buettcher M, Cetin BS, Bilogortseva O, Chechenyeva V, Demirjian A, Shackley F, McFetridge L, Speirs L, Doherty C, Jones L, McMaster P, Murray C, Child F, Beuvink Y, Makwana N, Whittaker E, Williams A, Fidler K, Bernatoniene J, Song R, Oliver Z, Riordan A (2020) COVID-19 in children and adolescents in Europe: a multinational, multicentre cohort study. Lancet Child Adolesc Health 4(9):653-666

8. Roland D, Harwood R, Bishop N, Hargreaves D, Patel S, Sinha I (2020) Children's emergency presentations during the COVID-19 pandemic. Lancet Child Adolesc Health 4(8):e32-e33

9. Maunder RG, Lancee WJ, Balderson KE, Bennett J, Borgundvaag B, Evans S, Fernandes C, Goldbloom D, Gupta M, Hunter J, McGillis Hall L, Nagle L, Pain C, Peczeniuk S, Raymond G, Read N, Rourke S, Steinberg R, Stewart T, VanDeVelde-Coke S, Veldhorst G, Wasylenki D (2006) Long-term psychological and occupational effects of providing hospital healthcare during SARS outbreak. Emerg Infect Dis 12:1924-1932

10. Mehta P, McAuley DF, Brown M, Sanchez E, Tattersall RS, Manson JJ, HLH Across Speciality Collaboration, UK (2020) HLH Across Speciality Collaboration, UK. COVID-19: consider cytokine storm syndromes and immunosuppression. Lancet 395(10229):1033-1034

11. Harwood R, Allin B, Jones CE et al (2020) PIMS-TS National Consensus Management Study Group. A national consensus management pathway for paediatric inflammatory multisystem syndrome temporally associated with COVID-19 (PIMS-TS): results of a national Delphi process. Lancet Child Adolesc Health S23524642(20):30304-30307

12. Berce V, Tomazin M, Gorenjak M, Berce T, Lovrenčič B (2019) The usefulness of lung ultrasound for the aetiological diagnosis of community-acquired pneumonia in children. Sci Rep 9(1):17957

13. Buonsenso D, Pata D, Chiaretti A (2020) COVID-19 outbreak: less stethoscope, more ultrasound. Lancet Respir Med S2213-2600(20): 30120-3012X

14. Buonsenso D, Raffaelli F, Tamburrini E, Biasucci DG, Salvi S, Smargiassi A, Inchingolo R, Scambia G, Lanzone A, Testa AC, Moro F (2020) Clinical role of lung ultrasound for the diagnosis and monitoring of COVID-19 pneumonia in pregnant women. Ultrasound Obstet Gynecol 56(1):106-109

15. Guan W-J, Ni Z-Y, Hu Y, Liang WH, Ou CQ, He JX, Liu L, Shan H, Lei CL, Hui DSC, du B, Li LJ, Zeng G, Yuen KY, Chen RC, Tang CL, Wang T, Chen PY, Xiang J, Li SY, Wang JL, Liang ZJ, Peng YX, Wei L, Liu Y, Hu YH, Peng P, Wang JM, Liu JY, Chen Z, Li G, Zheng ZJ, Qiu SQ, Luo J, Ye CJ, Zhu SY, Zhong NS, China Medical Treatment Expert Group for Covid-19 (2020) Clinical characteristics of coronavirus disease 2019 in China. N Engl J Med 382:1708-1720

Publisher's note Springer Nature remains neutral with regard to jurisdictional claims in published maps and institutional affiliations. 